\title{
DOENÇA LINFOPROLIFERATIVA PÓS-TRANSPLANTE TRATADA COM RITUXIMAB E SIROLIMUS: RELATO DE CASO E REVISÃO DA LITERATURA
}

\author{
Post-transplant lymphoproliferative disorder treated with rituximab and sirolimus: \\ case report and review of literature.
}

\begin{abstract}
Marcus Vinícius de Pádua Netto ${ }^{1,2}$, Henrique Vieira de Lima ${ }^{1,2}$, Ana Paula de Souza Borges ${ }^{1}$, Eduardo Moreira dos Santos ${ }^{2}$; Émerson Nunes Costa ${ }^{1,2}$; Luiz Cláudio Pádua Netto ${ }^{1}$
\end{abstract}

\begin{abstract}
RESUMO
Apesar dos benefícios do uso de imunossupressores para prevenir perda do enxerto no transplante renal, eles apresentam vários efeitos colaterais, entre eles as doenças linfoproliferativas que levam, por vezes, à necessidade de redução ou até mesmo da retirada total das drogas imunossupressoras, com risco de rejeição ao enxerto.

Relatamos um caso de um paciente branco, 20 anos, portador de insuficiência renal crônica secundária à Síndrome de Prune Belly, tendo iniciado hemodiálise em 2004, e, após seis meses, submetido a transplante renal e mantida imunossupressão com Tacrolimus, Micofenolato mofetil e Prednisona. No quarto mês pós-transplante renal desenvolveu quadro de doença linfoproliferativa pós-transplante, sendo então retirados imediatamente o Tacrolimus e Micofenolato mofetil, mantido apenas com Prednisona. Após aproximadamente um mês da retirada da imunossupressão, como não houve boa resposta com a redução da imunossupressão associada à terapia antiviral, optamos pela associação de Rituximab ao tratamento, com acompanhamento através de tomografia computadorizada, mostrando remissão total da esplenomegalia e da linfadenomegalia. Baseados em dados da literatura, foi associado Sirolimo à imunossupressão do paciente e mantida Prednisona com boa evolução após dois anos de seguimento.
\end{abstract}

Descritores: Transplante Renal; Transtornos Linfoproliferativos; Sirolimo, Imunossupressão.

Instituições:

1 Disciplina de Clínica Médica da Faculdade de Medicina da Universidade Presidente Antônio Carlos - UNIPAC - Araguari /MG

2 Departamento de Clínica Médica da Faculdade de Medicina da Universidade Federal de Uberlândia - Uberlândia/MG

Correspondência:

Marcus Vinícius Pádua Netto,

Rua Marques Póvoa, 513 apto 801

CEP 38400-438 - Uberlândia - MG - Brasil

Telefone: 34 3236-3079

E-mail:marcus@nanet.com.br; marcus-netto@uol.com.br

Recebido em: 28.05.2007

Aceito em: 25.06.2007

\section{RELATO DO CASO}

Homem branco de 20 anos, portador de insuficiência renal crônica decorrente da Síndrome de Prune Belly foi submetido a transplante renal doador vivo relacionado (mãe) em junho de 2005, e mantido em acompanhamento ambulatorial com boa evolução com uso de Micofenolato mofetil (MMF) 2g/dia, Tacrolimus (TAC) 10mg/dia, Prednisona (PRED) 7,5 mg/dia e Sulfametoxazol/Trimetropim 400/180 mg/dia.

Após quatro meses do transplante renal, em outubro de 2005, o paciente iniciou com odinofagia, hiperemia e edema de orofaringe, com placas purulentas nas tonsilas palatinas, sem febre. Diagnosticada amigdalite bacteriana aguda, foi prescrito Clindamicina $600 \mathrm{mg}$ de $8 / 8$ horas por 14 dias, porém, sem melhora clínica; foi substituída por Ceftriaxone $1 \mathrm{~g}$ de 12/12 horas e Amoxacilina 500mg de 8/8 horas por 14 dias, agora, com resposta terapêutica relativa. Não havia relato no prontuário médico da presença de massa cervical naquele momento.

Passados dois meses do tratamento anterior, em dezembro de 2005 o paciente apresentou quadro de enterorragia importante, evoluindo com instabilidade hemodinâmica e necessidade de hemotransfusão (21 unidades). Foi realizada colonoscopia, evidenciando-se úlcera retal solitária sangrante, não tendo sido feita biópsia local, e que foi tratada com escleroterapia com adrenalina e o paciente, agora 
estabilizado, encaminhado ao serviço de Nefrologia do Hospital de Clínicas para avaliação e seguimento.

À admissão, observou-se grande massa cervical à esquerda, segundo o paciente, de crescimento progressivo (inicialmente com $5 \mathrm{~cm}$ ) com sinais flogísticos, febre de $38,5^{\circ} \mathrm{C}$ e relato de perda ponderal de 4 kg em um mês. Realizada tomografia de crânio, constatou-se que a massa era compatível com um linfonodo cervical; à tomografia de abdome, viu-se esplenomegalia e nódulos hipoecogênicos no baço (figura 1).

A sorologia para vírus Epstein-Barr (EBV) que nos exames prétransplante do paciente era negativa, mostrou-se agora positiva e a biópsia da massa cervical foi compatível com Linfoma não-Hodking (LND) de grandes células B.

Confirmado o diagnóstico de $P T L D$ associada à infecção recente pelo EBV, foi iniciado tratamento com Ganciclovir $250 \mathrm{mg}$ duas vezes ao dia e suspensão rápida da imunossupressão (TAC e MMF), mantendo-se apenas com PRED 10mg/dia.

Diante da gravidade da apresentação do quadro, da má resposta inicial ao tratamento com a retirada da imunossupressão associada à terapia antiviral, com persistência da massa cervical e da esplenomegalia, da piora progressiva e mantida a função renal com a suspensão da imunossupressão, foi optado por utilizarmos Rituximab (MABTERA ${ }^{\circledR}$ ), $375 \mathrm{mg} / \mathrm{m} 2 /$ dose $(500 \mathrm{mg}$ ) EV em um total de quatro ciclos realizados semanalmente. O paciente evoluiu bem, apresentando boa resposta com a terapia e, clinicamente, redução total da massa cervical e esplenomegalia, confirmados por tomografia e recebendo alta após quatro semanas em uso de Prednisona 10mg/dia e Aciclovir 400mg 5x/dia.

Após seguimento de dois meses, com o paciente mantendo-se assintomático, sem massas palpáveis e com função renal estável $(\mathrm{Cr}=1.6 \mathrm{mg} / \mathrm{dl})$, diante dos relatos da literatura dos benefícios do uso dos inibidores do sinal de proliferação (sirolimus e everolimus), optamos por associar o Sirolimus (SRL) à imunossupressão à dose de $1 \mathrm{mg} /$ dia, sendo o nível sérico monitorizado mensalmente e mantido em torno de $5 \mathrm{ng} / \mathrm{ml}$ (VN: $5-10 \mathrm{ng} / \mathrm{ml}$ ), reduzindo a PRED para $5 \mathrm{mg} /$ dia.

Atualmente, o paciente encontra-se em acompanhamento ambulatorial em uso de SRL 1mg/dia, PRED 5mg/dia, enalapril $5 \mathrm{mg} /$ dia e omeprazol $10 \mathrm{mg} /$ dia, mantém função renal estável $(1,3 \mathrm{mg} / \mathrm{dl})$, sem nenhum gânglio palpável e a tomografia de abdome controle mostrou-se normal, sem linfadenomegalias e/ou esplenomegalia.

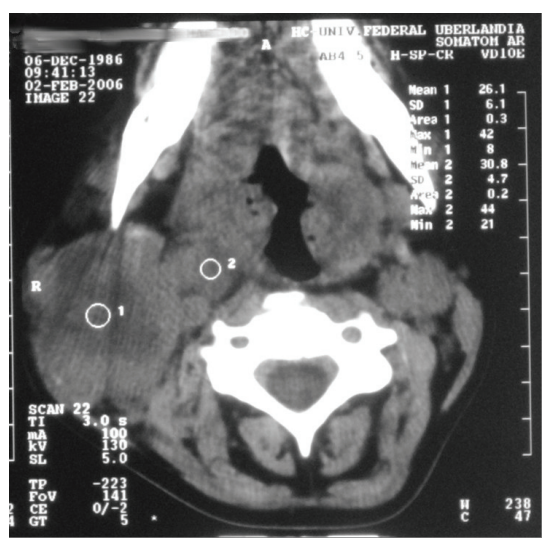

Figura 1: Adenomegalia cervical à esquerda na admissão do paciente
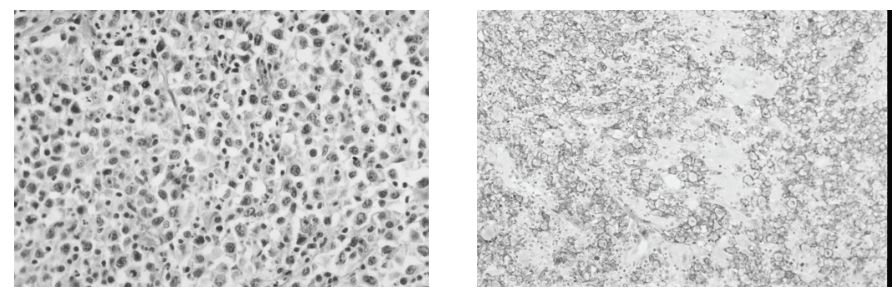

Figura 2: à esquerda, histopatologia compatível com LNH difuso de células B; à direita, imunohistoquímica mostrando-se positiva para CD-20.

O controle sorológico para EBV de setembro de 2006 revelou-se ainda positivo para IgM, porém, com redução dos títulos anteriores de IgG. Como confirmação e segurança para retirada da terapia antiviral foi solicitada pesquisa de capsídio viral para EBV, que se mostrou negativa e permaneceu negativa em pesquisas posteriores.

\section{DISCUSSÃO}

O termo doença linfoproliferativa pós-transplante é comumente aplicado para um grupo heterogêneo de doenças caracterizadas pela proliferação linfóide anormal que acomete pacientes farmacologicamente imunodeprimidos submetidos a transplantes de órgãos sólidos ou transplante de medula óssea.1 Aproximadamente 90\% dos casos de PTLD estão relacionados a infecções pelo EBV e tumores sólidos constituídos por células B CD-20 positivas. ${ }^{1}$

É uma complicação pouco freqüente pós-transplante de órgãos sólidos, com incidência variando entre $1 \%$ e $10 \%$, sendo mais expressiva a sua ocorrência após os transplantes hepáticos, cardíacos, pulmonares e de medula óssea. ${ }^{2,3,4}$

A imunossupressão leva à ineficiência da resposta imune celular efetiva, e o EBV, contando com essa resposta ineficaz dos linfócitos-T citotóxicos induz à proliferação descontrolada de linfócitos-B, culminando na formação de linfoma não-Hodking ${ }^{2,4}$.

Recentemente, Smith et al identificaram os principais fatores de risco para o desenvolvimento de linfoma em pacientes após o transplante renal: a idade, a raça e o tempo decorrido do transplante. Dentre os pacientes transplantados, o risco foi duas vezes maior em relação àqueles que permaneciam em programa dialítico à espera do transplante e o risco entre os caucasianos foi duas vezes maior do que entre os afro-americanos. ${ }^{5}$ Neste estudo, havia importante diminuição do risco após o primeiro ano pós-transplante, dado esse contrário ao achado em outros relatos. ${ }^{6,7}$

Pacientes jovens estão expostos a maior risco de primo infecção pelo EBV, seja no pós-transplante imediato, quando o vírus pode ser transmitido pelo enxerto, seja em qualquer outro momento, pela aquisição do vírus da comunidade. ${ }^{8} \mathrm{O}$ paciente no caso aqui descrito é jovem, de raça branca, com transplante realizado há menos de um ano, tendo apresentado sorologia negativa para EBV nos exames pré-transplantes, caracterizando um quadro de primo infecção, porém, não podemos afirmar se a primo infecção ocorreu a partir da transmissão pelo enxerto ou por contato com a comunidade, uma vez que não dispomos da sorologia da doadora.

O tratamento da PTLD ainda é controverso, consistindo da redução ou retirada da imunossupressão isolada ou associada ao uso de drogas antivirais como Aciclovir e Ganciclovir ${ }^{1,9}$. No entanto, essa estratégia pode desencadear a perda do enxerto quando 
da redução ou suspensão da imunossupressão, principalmente em transplantes recentes, como no caso relatado, por favorecer o desenvolvimento de rejeição aguda. Em alguns serviços, a ressecção do tumor também tem sido utilizada, assim como a radioterapia e a quimioterapia, com todos os graves efeitos colaterais que o tratamento quimioterápico apresenta. ${ }^{9}$

É de grande importância o fato que a maioria das células que constituem o linfoma expressam o receptor CD-20, pois ele é o alvo do Rituximab, um anticorpo monoclonal quimérico que tem se mostrado eficaz para o tratamento de Linfomas não-Hodking em pacientes imunocompetentes..$^{10} \mathrm{~A}$ ação dessa droga se faz por meio da ligação a esse receptor, induzindo tanto à apoptose quanto à lise celular mediada por complemento. ${ }^{11}$ Nos casos de $P T L D$, há relatos de sua associação com a retirada da imunossupressão, mostrando sucesso e diminuindo a necessidade de quimioterapia, bem como o número de comorbidades associadas ao tratamento. ${ }^{11}$

Um grande estudo retrospectivo multicêntrico onde pacientes foram tratados com Rituximab após redução da terapia imunossupressora mostrou o sucesso da terapia em 32 portadores de PTLD. ${ }^{12}$ Ganne et al, em uma série de oito pacientes, obtiveram remissão com boa preservação do enxerto em sete casos, e o paciente que não respondeu ao Rituximab foi então tratado com quimioterapia. ${ }^{2}$

No nosso paciente, a terapia inicialmente proposta foi suspensão total e abrupta da medicação imunossupressora, associada ao uso de terapia antiviral inicialmente com Gangiclovir. Porém, devido à falha na resposta ao tratamento com persistências da massa cervical, da hipertrofia amigdaliana da esplenomegalia e piora da função do enxerto, optamos pela terapia com Rituximab associado à terapia antiviral e redução da imunossupressão, quando então obtivemos boa resposta clínica, além da melhora e estabilização da função do enxerto.

A sobrevida de pacientes portadores de PTLD, apesar dos diferentes esquemas terapêuticos utilizados, continua sendo baixa. Porém, um estudo onde foi avaliada sobrevida de um, três e cinco anos utilizando o Rituximab em uma das seguintes formas: como primeira opção terapêutica; após falha da terapia primária; profilaticamente após resolução da PTLD mostrou sobrevida em um ano de $60 \%, 53 \%$ e $100 \%$; em três anos, de $40 \%, 33,3 \%$ e $100 \%$ e em cinco anos de $40 \%, 33,3 \%$ e $33,3 \%$, respectivamente. ${ }^{12}$

O número de sítios acometidos pela PTLD parece ser o fator prognóstico mais importante, sendo que com a doença presente em mais de dois sítios, a sobrevida em cinco anos é zero; em um ou dois outros lugares, em torno de $40 \% .12$

No caso em discussão, a PTLD ocorreu em dois sítios, linfonodo cervical e baço. Como houve falha no tratamento proposto inicialmente, a associação de quatro ciclos de Rituximab à redução da imunossupressão e terapia antiviral com Ganciclovir/Aciclovir fez com que obtivéssemos então sucesso terapêutico.
Um grande problema pode ser criado na situação clínica acima descrita, onde a retirada da imunossupressão para tratamento dos casos de PTLD aumenta os riscos de rejeição ao enxerto, principalmente nos transplantes de coração e pulmão. ${ }^{1}$ Com isso, dois importantes dilemas surgem para ser decidido: a imunossupressão deve ser retirada ou reduzida? Deveria ser mudado o esquema imunossupressor para diminuir a progressão do câncer ou mesmo destruir o câncer?

Alguns autores têm descrito como relatos de casos em modelos clínicos e experimentais a segurança e a efetividade no tratamento da PTLD da associação do Rituximab com SRL, bem como seu efeito na redução de metástases, inibindo a proliferação de linfomas de células B EBV positivas e o aparecimento de tumores primários, tendo como fatores fundamentais de sua ação a interrupção do ciclo celular através da diminuição dos níveis séricos das ciclinas D2 e D3, diminuição das ciclinas dependentes da Kinase 4 (CNK) e aumento da expressão de inibidores de CNK. ${ }^{13,14,15,16,17 .}$

A piora da função renal do paciente antes da introdução do Rituximab poderia estar relacionada ao desenvolvimento da rejeição ao enxerto desencadeado pela diminuição da imunossupressão em transplante ainda recente, embora não tivéssemos como descartar a possibilidade de nefrotoxicidade causada pelos antibióticos e antivirais utilizados durante o tratamento, ou mesmo outras causas, uma vez que não foi possível realizar biópsia renal devido ao risco de sangramento demonstrado por alterações laboratoriais (INR), alterações essas atribuídas ao grande volume de sangue transfundido após o sangramento intestinal antes da admissão em nosso serviço (20 bolsas).

Para tanto, com o objetivo de preservar o enxerto e, talvez, colaborar no tratamento anti-neoplásico evitando recidivas e prolongando a sobrevida tanto do enxerto quanto do paciente, optamos por iniciar terapia imunossupressora com SRL associada à PRED, como terapia de manutenção do transplante renal. Oito meses após o diagnóstico, o paciente apresenta função renal estável, PCR real-time para EBV, que serve para avaliar a quantidade de DNA do EBV no sangue periférico e pode detectar de duas a mais de $10^{7}$ cópias de DNA no sangue, garantindo a ausência completa do vírus responsável pelo aparecimento da PTLD e, assim, a remissão do tumor é mantida.

\section{CONCLUSÃO}

A terapia com o Rituximab associada ao SRL, redução da imunossupressão e terapia antiviral parecem ser eficazes e seguras, e devem ser consideradas para o tratamento da PTLD. Porém, apesar desse esquema ter sido utilizado e de ter demonstrado sucesso no tratamento do nosso caso, maiores estudos são essenciais para a confirmação da sua eficácia em longo prazo.

\section{ABSTRACT}

Despite the benefits of the immunosuppressive medications to improve the graft function, they present several adverse effects, such as development of post-transplant lymphoproliferative disorder in renal transplant recipients needing sometime a drastic reduction or withdrawal of the Immunosuppression and the consequent risk for graft rejection. 
We report a 20-year-old white man with chronic renal failure diagnosis secondary to Plune Belly Syndrome that started hemodialisys therapy in 2004, and after six months, his mother offered to donate a kidney to him; he was treated with Tacrolimus, Mofetil Mycophenolate and Prednisone. Four months later, a post-transplant lymphoproliferative diagnosis was made, and the Tacrolimus and Mofetil Mycophenoplate were suddenly discontinued. There was no response, and Rituximab was associated, when the computed tomography showed regression of splenomegaly and remission of the lymphadenomegaly. Based on the benefit reported in the literature, Sirolimus was associated to Prednisone in the Immunosuppression maintenance.

Keywords: Kidney Transplantation; Lymphoproliferative Disorders; Sirolimus, Immunosuppression.

\section{REFERÊNCIAS BIBLIOGRÁFICAS}

1. Frey NV, Tsai DE. The management of post transplant lymphoproliferative disorder Medical Oncology. 2007;24(2):125-36.

2. Ganne V, Siddiq N, Kamaplath B, Chung-Che C, Cohen E, Bresnahan BA, Hariharan $\mathrm{SN}$, et al. Humanized anti-CD20 monoclonal antibody (Rituximab) treatment for post-transplant lymphoproliferative disorder: Clin. Tranplant. 2003;17(5):417-22.

3. Shapiro R, Nalesnik. M, McCauley J, Fedorek S, Jordan ML, Scantlebury VP, et al. Posttransplant lymphoproliferative disorders in adult and pediatric renal transplant patients receiving Tacrolimus based imunossupression. Transplantation. 1999;68(12):1851-4.

4. Starzl TE, Nalesnik MA, Porter KA, Ho M, Iwatsuki S, Griffith BP, et al. Reversibility of Linphomas and Limphoproliferative Lesions Developing Under Ciclosporinesteroide Therapy. Lancet. 1984;1(8377):583-7.

5. Smith JM, Rudser K, Gillen D, Kestenbaun B, Seliger S, Weiss N. Risk of Lymphoma after Renal Transplantation Varies with Time: An Analysis of the United States Renal Data System. Transplantation. 2006;81(2):175-80.

6. Grillo-Lopez AJ, White CA, Dallaire BK, Varns CL, Shen CD, Wei A, Leonard JE, McClure A, Weaver R, Cairelli S, Rosenberg J. Rituximab: the first monoclonal antibody approved for the treatment of lymphoma. Curr Pharm Biotecnol. 2000;1(1):1-9.

7. Opelz G, Dohler B. Lymphoma after solid organ transplantation: a collaborative transplant study report. Am J Transplant. 2004;4(2):222-30.

8. Cockfield SM, Preiksaitis JK, Jewell LD, Parfrey NA. Post-transplant lymphoproliferative disorder in renal allograft recipients: clinical experience and risk factor analysis in a single center. Transplantation. 1993;56(1):88-96.

9. Green, M. Management of Epstein-Bar Virus induced post-transplant lymphoproliferative disease in recipients of solid organ transplantation. Am. J. Transplant. 2001;1(2):103-7.
10. Jain AB, Amadeo M, Pokharna L, Shapiro R, Fontes PA, Wallace M, et al. Rituximab (Chimeric Anti-CD20 Antibody) for Post-transplant lymphoproliferative disorder after solid organ transplantation in Adults: Long-term experience from a single center. Transplantation. 2005;80(12):1692-98.

11. Ganne V, Siddiq N, Kamaplath B, Chung-Che C, Cohen E, Bresnahan BA, Hariharan S. Humanized anti-CD20 monoclonal antibody (Rituximab) treatment for posttransplant lymphoproliferative disorder. Transplantation. 2003;17(5):417-22.

12. Koehl G E, Andrassy J, Guba M, Richter S, Kroemer A. Rapamycin protects allograft from rejection while simultaneously attacking tumors in immunosuppressed mice. Transplantation. 2004;77(9):1319-26.

13. Luan FL, Ding R, Sharma VK, Chon WJ, Lagman M, Suthanthiran M. . Rapamycin is an effective inhibitor of human renal cancer metastasis. Kidney Int. 2003; 63:917-27.

14. Cullis B, D'Souza R, McCullagh P, Harries S, Nicholls A, Lee R, Bingham C. Sirolimus-Induced Remission of Posttransplantation Lymphoproliferative Disorder. Am J Kidney Dis. 2006;47:e67-72.

15. Vaysberg M, Balatoni EC, Nepomuceno RR, Krams SM, Martinez OM. Rapamycin Inhibits Proliferation of Epstein-Barr Virus-Positive B-cell Lymphomas Through Modulation of Cell-Cycle Protein Expression Transplantation. 2007;83(8):1114-21.

16. Garcia VD ; Neumann J.J; Fogliatto L.; Geiger A, Garcia C; Vivianne Barros V.; et al. Rituximab in Association with Rapamycin for Post-transplant Lymphoproliferative Disease Treatment. Transplant Int. 2003;16(3):202-6.

17. Oerlet SHK, Verschuuren E, Reinke P, Zeidler K, Papp-Váry M, Babel M, Trappe RU, Jonas S, Hummel M, Anagnostopoulos I, Dörken B, Riess HB. Effects of anti-CD20 antibody Rituximab in Patients with Post-transplant Lymphoproliferative Disorder (PTLD). Am J Transplant. 2005;5(12):2901-06. 


\section{NORMAS DE PUBLICAÇÃO}

O JBT - Jornal Brasileiro de Transplantes, ISSN 1678-3387, órgão oficial da ABTO - Associação Brasileira de Transplante de Órgãos, destina-se à publicação de artigos da área de transplante e especialidades afins, escritos em português, inglês ou espanhol.

Os manuscritos submetidos à Revista, que atenderem às "Instruções aos Autores" e estiverem de acordo com a política Editorial da Revista, após aprovação pelo Conselho Editorial, serão encaminhados para análise e avaliação de dois revisores, sendo o anonimato garantido em todo o processo de julgamento. Os comentários serão devolvidos aos autores para as modificações no texto ou justificativas de sua conservação. Somente após aprovação final dos editores e revisores, os trabalhos serão encaminhados para publicação. Serão aceitos Artigos Originais, Artigos de Revisão, Apresentação de Casos Clínicos, Cartas ao Editor, Ciências Básicas Aplicadas aos Transplantes, Opinião Técnica, Prós e Contras, Imagem em Transplante e Literatura Médica e Transplantes.

\section{ARTIGOS ORIGINAIS:}

São trabalhos destinados à divulgação de resultados da pesquisa científica. Devem ser originais e inéditos. Sua estrutura deverá conter os seguintes itens: Resumo (português e inglês), Introdução, Métodos, Resultados, Discussão, Conclusão e Referências. Devem ter, no máximo, 45 referências.

\section{ARTIGOS DE REVISÃO:}

Constituem da avaliação crítica e sistemática da literatura sobre um assunto específico, podendo ser: Revisão Acadêmica, Revisão de Casos, Revisões Sistemáticas, etc. $\mathrm{O}$ texto deve esclarecer os procedimentos adotados na revisão, a delimitação e os limites do tema, apresentar conclusões e ou recomendações e ter, no máximo, 60 referências.

\section{APRESENTAÇÃO DE CASOS CLÍNICOS:}

Relata casos de uma determinada doença, descrevendo seus aspectos, história, condutas, etc... incluindo breve revisão da literatura, com 20 referências, no máximo.

\section{CARTAS AO EDITOR:}

Tem por objetivo discutir trabalhos publicados na revista ou relatar pesquisas originais em andamento. Devem ter, no máximo, três laudas e cinco referências.

\section{CIÊNCIAS BÁSICAS APLICADAS AOS TRANSPLANTES:}

Artigos de revisão sobre temas de ciência básica, cujo conhecimento tem repercussão clínica relevante para Transplantes. Devem ter, no máximo, dez laudas e 15 referências e serão feitas apenas a convite do JBT.

\section{OPINIÃO TÉCNICA:}

Destina-se a publicar uma resposta a uma pergunta de cunho prático através de opinião de um especialista (Quem? Quando? Como? Onde? Por quê?). Devem ter, no máximo, seis laudas e apresentarem até quinze referências.

\section{PRÓS E CONTRAS:}

Frente a uma questão, dois autores serão escolhidos pela editoria do JBT, para discutirem os aspectos positivos e os negativos de um assunto controvertido. São dois autores, um escrevendo a favor e o outro contra uma determinada proposição. Cada autor deve escrever no máximo três laudas e cinco referências.

\section{IMAGEM EM TRANSPLANTE:}

Uma imagem relacionada a Transplante, patognomônica, típica, de US, RX, CT, RNM, foto de cirurgia, microscopia, sinal clínico, etc., seguida de um texto curto, explicativo, com, no máximo, 15 linhas e três referências.

\section{LITERATURA MÉDICA E TRANSPLANTES}

Um artigo original de qualquer área médica, incluindo transplantes, que seja importante para o conhecimento do médico transplantador, poderá ser revisado, e o resumo do trabalho original será publicado, seguido de um pequeno resumo comentado ressaltando sua importância. O resumo deve ter até duas laudas e apresentar a referência completa do trabalho. Autores serão convidados para esse tipo de publicação, mas poderão ser considerados para publicação no JBT trabalhos enviados sem convites quando considerados relevantes pelos editores.

\section{PONTO DE VISTA}

Temas sobre transplantes de órgãos ou tecidos, elaborados por autores da área, convidados pela editoria da revista. Deverão conter 1.200 palavras, no máximo.

As normas que se seguem, devem ser obedecidas para todos os tipos de trabalhos e foram baseadas no formato proposto pelo International Committee of Medical Journal Editors e publicado no artigo: Uniform requirements for manuscripts submitted to biomedical journals. Ann Intern Med 1997;126;36-47, e atualizado em outubro de 2001. Disponível no endereço eletrônico: http://www.icmje.org

\section{NORMAS PARA ELABORAÇÃO DO MANUSCRITO}

\section{Requisitos técnicos}

a) O trabalho deverá ser digitado em espaço duplo, fonte Arial tamanho 12, margem de 2,5 cm de cada lado, com páginas numeradas em algarismos arábicos, na sequiência: página de título, resumos e descritores, texto, agradecimentos, referências, tabelas e legendas. Se impresso, deverá ser enviada uma via, em papel tamanho ISO A4 (212×297mm), mais uma cópia digital (CD-ROM).

b) Permissão à ABTO para reprodução do material.

c) Declaração que o manuscrito não foi submetido a outro periódico,

d) Aprovação de um Comitê de Ética da Instituição onde foi realizado o trabalho, quando referente a trabalhos de pesquisa envolvendo seres humanos.

e) Termo de responsabilidade do autor pelo conteúdo do trabalho e de conflitos de interesses que possam interferir nos resultados.

\section{Observações:}

1) Com exceção do item “a”, os documentos acima deverão conter a assinatura do primeiro autor, que se responsabiliza pela concordância dos outros co-autores.

2) Há em nosso site, modelo de carta para acompanhar os trabalhos, onde já constam as informações referentes aos itens b, c, d, e.

Após as correções sugeridas pelos revisores, a forma definitiva do trabalho deverá ser encaminhada, preferencialmente, por e-mail ou, uma via impressa, acompanhada de CD-ROM. Os originais não serão devolvidos. Somente o JBT-Jornal Brasileiro de Transplantes poderá autorizar a reprodução em outro periódico, dos artigos nele contidos.

\section{PREPARO DO MANUSCRITO}

A página inicial deve conter:

a) Título do artigo, em português (ou espanhol) e inglês, sem abreviaturas; que deverá ser conciso, porém informativo;

b) Nome completo de cada autor, afiliação institucional e região geográfica (cidade, estado, país);

c) Nome, endereço completo, fax e e-mail do autor responsável e a quem deve ser encaminhadas as correspondências;

d) Fontes de auxílio à pesquisa, se houver.

\section{RESUMO E ABSTRACT}

Para os artigos originais, os resumos devem ser apresentados no formato estruturado, com até 350 palavras destacando: os objetivos, métodos, resultados e conclusões. Para as demais seções, o resumo pode ser informativo, porém devendo constar o objetivo, os métodos usados para levantamento das fontes de dados, os critérios de seleção dos trabalhos incluídos, os aspectos mais importantes discutidos, as conclusões e suas aplicações.

Abaixo do resumo e abstract, especificar no mínimo três e no máximo dez des- 
critores (keywords), que definam o assunto do trabalho. Os descritores deverão ser baseados no DeCS (Descritores em Ciências da Saúde) publicado pela Bireme que é uma tradução do MeSH (Medical Subject Headings) da National Library of Medicine e disponível no endereço eletrônico: http://decs.bvs.br.

Os resumos em português (ou espanhol) e inglês deverão estar em páginas separadas. Abreviaturas devem ser evitadas.

\section{TEXTO}

Iniciando em nova página, o texto deverá obedecer à estrutura exigida para cada tipo de trabalho (vide acima). Com exceção de referências relativas a dados não publicados ou comunicações pessoais, qualquer informação em formato de "notas de rodapé” deverá ser evitada.

\section{AGRADECIMENTOS}

Após o texto, em nova página, indicar os agradecimentos às pessoas ou instituições que prestaram colaboração intelectual, auxílio técnico e ou de fomento, e que não figuraram como autor.

\section{REFERÊNCIAS}

As referências devem ser numeradas consecutivamente, na mesma ordem em que foram citadas no texto e identificadas com números arábicos, sobrescritos, após a pontuação e sem parênteses.

A apresentação deverá estar baseada no formato denominado "Vancouver Style", conforme exemplos abaixo, e os títulos de periódicos deverão ser abreviados de acordo com o estilo apresentado pela List of Journal Indexed in Index Medicus, da National Library of Medicine e disponibilizados no endereço:

http://www.ncbi.nlm.nih.gov/entrez/linkout/journals/jourlists.cgi?typeid=1\&ty pe $=$ journals \&operation $=$ Show

Para todas as referências, cite todos os autores até seis. Acima de seis, cite os seis primeiros, seguidos da expressão et al. Alguns exemplos:

\section{ARTIGOS DE PERIÓDICOS}

Donckier V, Loi P, Closset J, Nagy N, Quertinmont E, Lê Moine O, et al. Preconditioning of donors with interleukin-10 reduces hepatic ischemia-reperfusion injury after liver transplantation in pigs. Transplantation. 2003;75:902-4

Papini H, Santana R, Ajzen, H, Ramos, OL, Pestana, JOM. Alterações metabólicas e nutricionais e orientação dietética para pacientes submetidos a transplante renal. J Bras Nefrol. 1996;18:356-68.

\section{RESUMOS PUBLICADOS EM PERIÓDICOS}

Raia S, Massarollo PCP, Baia CESB, Fernandes AONG, Lallee MP, Bittencourt $P$ et al. Transplante de fígado "repique": receptores que também são doadores [resumo]. JBT J Bras Transpl. 1998;1:222.

\section{LIVROS}

Gayotto LCC, Alves VAF. Doenças do fígado e das vias biliares. São Paulo: Atheneu; 2001.

Murray PR, Rosenthal KS, Kobayashi GS, Pfaller MA. Medical microbiology. 4th ed. St. Louis: Mosby; 2002.

\section{CAPÍTULOS DE LIVROS}

Raia S, Massarollo PCB. Doação de órgãos. In: Gayotto LCC, Alves VAF, editores. Doenças do fígado e das vias biliares. São Paulo: Atheneu; 2001. p.1113-20.

Meltzer PS, Kallioniemi A, Trent JM. Chromosome alterations in human solid tumors. In: Vogelstein B, Kinzler KW, editors. The genetic basis of human cancer. New York: McGraw-Hill; 2002. p. 93-113.

\section{TRABALHOS APRESENTADOS EM EVENTOS}

Sokal EM, Cleghorn G, Goulet O, Da Silveira TR, McDiarmid S, Whitington P. Liver and intestinal transplantation in children: Working Group Report [Presented at $1^{\circ}$.World Congress of Pediatric Gastroenterology, Hepatology and Nutrition] J Pediatr Gastroenterol Nutr 2002; 35 Suppl 2:S159-72.

\section{TESES}

Couto WJ, Transplante cardíaco e infecção [tese]. São Paulo:Universidade Federal de São Paulo; 2000.

Pestana JOM. Análise de ensaios terapêuticos que convergem para a individualização da imunossupressão no transplante renal [tese]. São Paulo: Universidade Federal de São Paulo; 2001.

\section{DOCUMENTOS ELETRÔNICOS}

Matsuyama M, Yoshimura R, Akioka K, Okamoto M, Ushigome H, Kadotani $\mathrm{Y}$, et al. Tissue factor antisense oligonucleotides prevent renal ischemia reperfusion injury. Transplantation [serial online] 2003 [cited 2003 Aug 25];76:786-91. Available from: URL: http://gateway2.ovid.com/ovidweb.cgi.

\section{HOMEPAGE}

Cancer-Pain.org [homepage na Internet]. New York: Association of Cancer Online Resources, Inc.; c2000-01 [atualizada em 2002 May 16; acesso em 2002 Jul 9]. Disponível em: http://www.cancer-pain.org/

\section{PARTE DE UMA HOMEPAGE}

American Medical Association [homepage na Internet]. Chicago: The Association; c1995-2002 [atualizada em 2001 Aug 23; acesso em 2002 Aug 12]. AMA Office of Group Practice Liaison; [aproximadamente 2 telas]. Disponível em: http://www.ama-assn.org/ama/pub/category/1736.html

Obs: Dados não publicados, comunicações pessoais, deverão constar apenas em "notas de rodapé". Trabalhos enviados para a revista devem ser citados como trabalhos no "prelo", desde que tenham sido aceitos para publicação. Deverão constar na lista de Referências, com a informação: [no prelo] no final da referência, ou [in press] se a referência for internacional.

\section{TABELAS, FIGURAS, LEGENDAS E ABREVIATURAS}

- Tabelas: Devem ser confeccionadas com espaço duplo. A numeração deve ser seqüencial, em algarismos arábicos, na ordem que foram citadas no texto. Devem ter título, sem abreviatura, e cabeçalho para todas as colunas. No rodapé da tabela deve constar legenda para abreviaturas e testes estatísticos utilizados. Devem ser delimitadas, no alto e embaixo por traços horizontais; não devem ser delimitadas por traços verticais externos e o cabeçalho deve ser delimitado por traço horizontal. Legendas devem ser acompanhadas de seu significado. No máximo, quatro tabelas deverão ser enviadas.

- Figuras: (gráficos, fotografias, ilustrações): As figuras devem ser enviadas no formato JPG ou TIF, com resolução de 300dpi, no mínimo. Ilustrações extraídas de outras publicações deverão vir acompanhadas de autorização por escrito do autor/editor, constando na legenda da ilustração a fonte de onde foi publicada. As figuras deverão ser enviadas em branco e preto.

- Legendas: Imprimir as legendas para as ilustrações usando espaço duplo, uma em cada página separada. Cada legenda deve ser numerada em algarismos arábicos, correspondendo a cada ilustração e na ordem que foram citadas no trabalho.

- Abreviaturas e Siglas: Devem ser precedidas do nome completo quando citadas pela primeira vez. Nas legendas das tabelas e figuras, devem ser acompanhadas de seu significado. Não devem ser usadas no título.

\section{ENVIO DO MANUSCRITO}

\section{Os trabalhos devem ser enviados para:} e-mail: abto@abto.org.br

ou

Jornal Brasileiro de Transplantes - JBT A/C Dr. Mário Abbud Filho

Av. Paulista, 2001, $17^{\circ}$ andar - Cj. 1704/1707

01311-300 - São Paulo - SP

(Tel/Fax.: 011-3283-1753) 